\title{
Cultural Heritage Destruction: Experiments with Parchment and Multispectral Imaging
}

\author{
Alberto Campagnolo*, Alejandro Giacometti \\ Lindsay MacDonald ${ }^{\dagger}$, Simon Mahony ${ }^{\dagger}$, \\ Melissa Terras ${ }^{\dagger}$ and Adam Gibson ${ }^{\dagger}$ \\ ${ }^{\star}$ University of the Arts, London, \\ †University College London
}

\begin{abstract}
This chapter describes a highly collaborative project in digital humanities, which used tools and expertise from a diverse range of disciplines: medical physics, image science, and conservation. We describe this collaboration through three examples: the use of phantoms taken from medical physics, a historically accurate model of parchment degradation, and a detailed description of the steps taken to run experiments and collect data within a manageable budget. Each example highlights how procedures from a discipline were adapted for the project through collaboration.

Whilst conservation focuses on developing methods to best preserve cultural heritage documents, we describe an unusual collaboration between conservation and image science to document through multispectral imaging the deliberate damage of a manuscript. Multispectral imaging has been utilised to examine cultural heritage documents by providing information about their physical properties. However, current digitisation efforts concentrate on recording documents in their current state. In this project, we aimed at recording the process
\end{abstract}

\section{How to cite this book chapter:}

Campagnolo, A, Giacometti, A, MacDonald, L, Mahony, S, Terras, M and Gibson, A. 2016. Cultural Heritage Destruction: Experiments with Parchment and Multispectral Imaging. In: Bodard, G \& Romanello, M (eds.) Digital Classics Outside the Echo-Chamber: Teaching, Knowledge Exchange \& Public Engagement, Pp. 121-146. London: Ubiquity Press. DOI: http://dx.doi.org/10.5334/bat.h. License: CC-BY 4.0. 
of macroscopic document degradation using multispectral imaging, and the digital recovery of the writing using standard image processing methodologies.

This project's success lay in the intersection of knowledge of the processes of parchment deterioration and the specific processes that occur when a document is imaged: this has permitted us to construct a more successful and informed experiment. The knowledge acquired during the project allows us to address the issues related to the recovery of information from damaged parchment documents, and to determine which research questions can be addressed, and through which imaging methodology.

\section{Introduction}

In this chapter we describe how a highly collaborative project in digital humanities used tools from several disciplines. This collaboration not only made the project more interesting, but was essential to its success. Previous publications and presentations on this research have described in detail the methodology and results. ${ }^{1}$ In this chapter, we complement those by focusing on the problems encountered throughout the project and the methodological challenges which could only be overcome though integration of the diverse range of expertise belonging to different, and yet complimentary, disciplines. We describe how this collaboration happened and the specific outcomes in three examples.

These include a description of how we transferred the concept of phantoms from medical physics research into the digital humanities, the methodology we developed to model historically accurate damage to manuscripts in order to reflect macroscopic damage, and a highly collaborative approach we used in order to be able to implement experiments and collect experimental data ${ }^{2}$ on a manageable budget. Data acquisition for multispectral imaging projects is relatively straightforward but does, however, require access to specialist-and usually expensive-imaging hardware. ${ }^{3}$ Similarly, gaining access to original material on which to experiment can be difficult and even quite costly at times. By bringing in expertise from different fields, we managed to circumvent these problems and each, looking outside their natural echo chamber, managed to hone their methodologies and practices to ensure the success of the common goals within the project.

We started by borrowing the idea of phantom tests from medical physics, and applied it to cultural heritage imaging in order to evaluate methods for recovery of writing from multispectral images of a palimpsest. However, a completely computer-based digital phantom required oversimplification of the problems which occur when parchment degrades. We therefore turned to conservation, seeking practical experience of working with original materials and knowledge of parchment behaviour. This expertise was considered in the context of the use of multispectral imaging on manuscripts. Finally, expertise on colour science was sought in order to optimise the data acquisition within a limited budget. 
In this chapter we bring together the experiences of working across a wide range of imaging, computing, and conservation areas, in order to develop best practice guidelines for others working with damaged and deteriorated documents. Working in such an interdisciplinary project, we present here, through three examples, the various factors which led to successful collaboration, including interactive planning, task distribution, consultation, institutional support, and communication.

\section{Case Study 1: Phantoms from medical imaging applied to cultural heritage}

A first example of how our project had to look outside of the usual echo chamber for its success is the production of imaging phantoms, borrowing a commonly used tool from the medical physics researcher's toolbox. Our approach to investigating multispectral imaging as applied to cultural heritage documents is centred on the design and application of imaging phantoms. These are tools often used in medical physics and for other scientific research. Phantoms are essentially a simplification of a physical research problem where tests and experiments can be carried out quickly and safely. Phantoms are used to test and compare new systems, calibrate prototypes, and iterate improvements quickly. ${ }^{4}$ Phantoms in medical physics research are similar to digital surrogates in the humanities; just as these surrogates allow the study of cultural heritage artefacts without further damaging the originals, phantoms allow experiments to be carried out without risking harm to patients.

When designing a phantom test, a researcher attempts to create a controlled environment which replicates a well defined but limited subset of the characteristics of a larger problem. Typically, a phantom in medical physics will include a simplified environment which simulates a patient, or part of a patient such as an organ or similar. The conditions in the experiment are controlled, thus the performance of a system can be tested thoroughly and compared to a known ground truth before testing it on a real patient. This simplified environment provides a fast and robust product development cycle which is independent of concerns about the safety of a patient.

Phantoms can be either a computer simulation of a digital model mimicking a real object on which one can test processing algorithms, or specially designed material objects mimicking specific characteristics of a real object. For example, often in medical imaging phantoms are produced from materials that mimic human tissue but with well-characterised material properties. The phantom can then be imaged with a new experimental technique, providing useful insight into the performance of the new technology. The construction and characterisation of phantoms is an important area of research. ${ }^{5}$ For example, Price et al. ${ }^{6}$ have developed a material that simulates breast tissue. This material was developed specifically to respond to breast compression and 
$\mathrm{X}$-rays in a similar way to breast tissue, so that it can be used by researchers to study the performance of new X-ray imaging techniques. Ionising radiation is dangerous to humans, and phantom materials such as this ensure that the patient is exposed to it only when necessary. Similarly, Levesque, Sled \& $\mathrm{Pike}^{7}$ present an iterative design methodology, aided by a phantom, to optimise systematically, and improve the signal to noise ratio of quantitative magnetisation transfer imaging, a specialised medical imaging technique. Tests can subsequently be performed directly on the patient once the technology and its effects are better understood.

The tradition of phantom development and testing has not yet become established as a research methodology in the humanities. In the world of conservation, and heritage science in particular, however, where new techniques are developed for the assessment, treatment, or recovery of cultural artefacts, the use of controlled degradation and synthetic and virtual models is more common. ${ }^{8}$ These tools are used with a similar purpose to that of phantom tests. Examples vary from the determination of the degree of deterioration of parchment samples through comparison with new, artificially-aged, and naturallyaged parchment, ${ }^{9}$ to the quantification of the deterioration effects of light damage on parchment through controlled UV irradiation on modern parchment tested before and after irradiation, ${ }^{10}$ to the aging characteristics of gelatines and animal glues used in conservation and their reversibility through tests on newly produced adhesive films. ${ }^{11}$ These experiments are not directly named as phantoms, but their execution is intended to perform a similar function: testing, comparing, optimising, and validating methodologies. Recently research appears to have begun explicitly utilising phantoms as research tools. Marengo et al. ${ }^{12}$ use virtual degradation of multispectral images of documents in order to evaluate an algorithm in controlled conditions. The algorithm they developed monitors the conservation condition of a document, based on information from multispectral images of the document. They manipulate the data in specific ways in order to train the algorithm, which they later apply to unadulterated images.

Finally, recent work in scrolled historical documents has used modelling and problem simplification to develop algorithms to digitally unroll and reconstruct the writing from scanned images of the documents. Scrolls that are too fragile and deteriorated to be physically unrolled present a difficult imaging problem, as most of the text is within the scroll and often is present on both sides of the parchment. Sub-surface imaging techniques have been used to scan these documents, but the writing typically remains illegible. Developing algorithms to digitally unroll these documents is challenging, but the use of laboratorycreated scrolls and digital models is proving to be more and more successful. ${ }^{13}$

In this project, we proposed a new method for assessing the effectiveness of image processing algorithms that are currently in use to recover information from degraded documents. The first step was designing and implementing a virtual model phantom to simulate the conditions that are common to palimpsest manuscripts. Figure 1 shows how we constructed a phantom simulation 

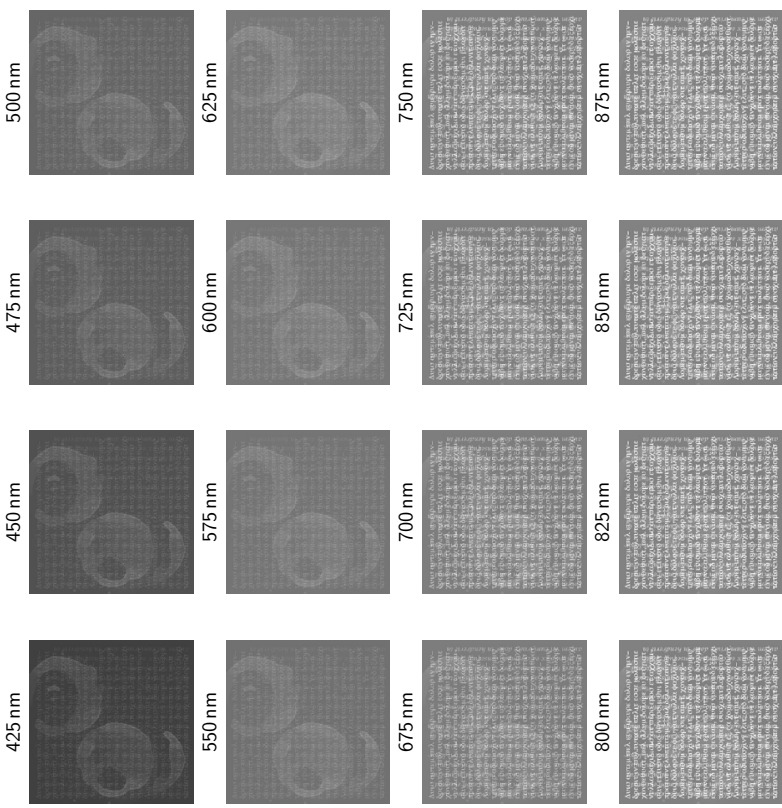
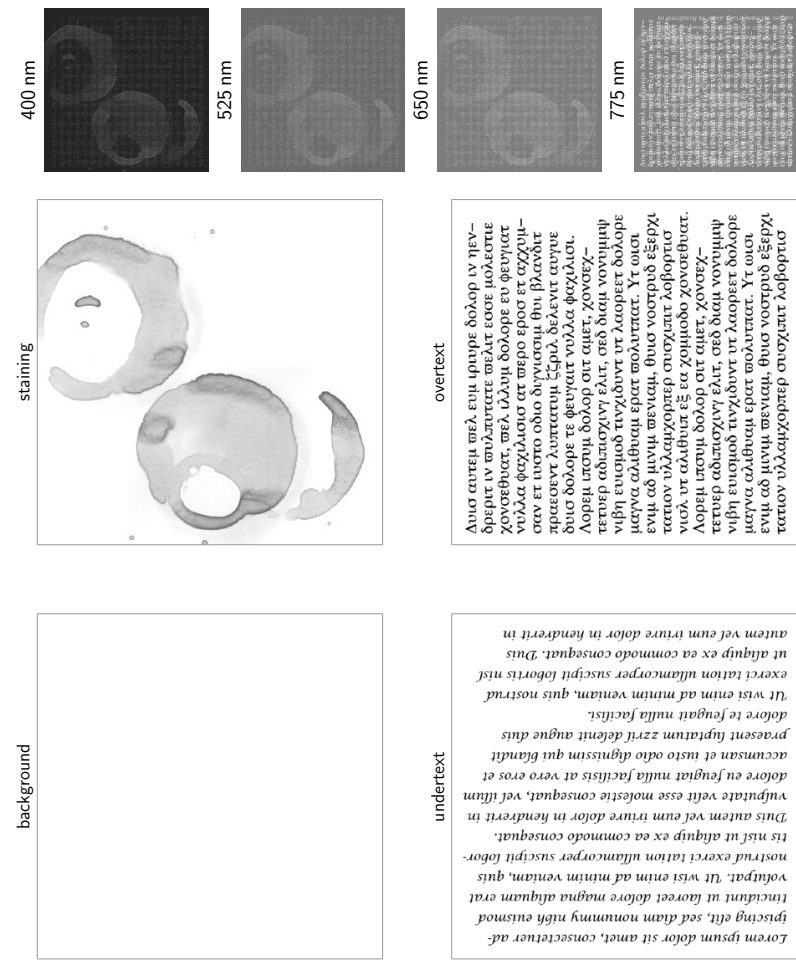

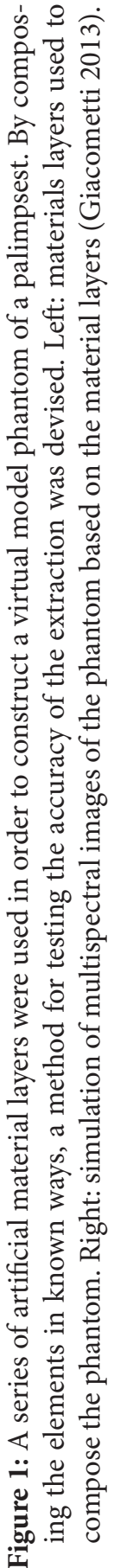


generated multispectral images with two layers of text, a background layer and a staining layer. A series of image processing algorithms were used to separate the components. A priori knowledge of the materials that contribute to the document and their arrangement in the document provides a ground truth which enables the evaluation of how the image processing algorithms perform at recovering the writing from the document. Once a basis for a comparison was available, we were able to propose a method to compare images of recovered information to the ground truth. The phantom was essential in devising an appropriate method to measure that performance. The method proposed later proved capable at handling experimental data. The phantom was based on methodologies from medical physics research. It was only able to be constructed once specific characteristics of palimpsests where understood and in the context of previous experimentation in conservation.

\section{Case Study 2: Historically accurate modelling of parchment damage designed for imaging purposes}

A second example is the design of a methodology to physically model macroscopic damage to parchment to provide a test platform for multispectral imaging processing algorithms. Following the hands-on approach typically found in conservation research, we identified the different types of damage parchment documents are likely to incur during their lives, from technological mistakes during production, to improper use, unsuitable storage condition, disasters, and natural ageing, ${ }^{14}$ we then subjected an original parchment document to a series of treatments aimed at mimicking these deterioration processes. Careful consideration was given to select this set of deteriorating agents which required expertise from conservation and image science. ${ }^{15}$

Accredited archives follow strict guidelines and policies on the deaccessioning of items from their collections. Whilst historical collections are usually preserved, on rare occasions, such as when material is duplicated, non-archival, or of no informational/evidential value, they can be deaccessioned, and disposed of by being transferred to other repositories, returned to owners, sold, or destroyed. ${ }^{16}$ Historical items sent to be destroyed may still be of substantial value as physical objects and may be donated to conservation studios or conservation training centres for experimentation and training on historical materials without risking damaging items of incontestable documentary value. We obtained, through this route, an 18th-century parchment document, deemed of no historical value, and deaccessioned from the London Metropolitan Archives' collections in accordance with The National Archives guidance on deaccessioning and disposal. ${ }^{17}$ Dated to 11 th of August 1753, it is an indenture, or land contract, between a Mr John Sherman and a Mr Christ Gardiner. Apart from some signs of wear and tear, especially around the fold, the parchment document was in overall good condition. The text had been handwritten in 
metallo-gallic ink on the recto (flesh side), with some information recorded also on the verso.

We chose to focus on parchment documents for our study, given that parchment remains the primary medium of large quantities of culturally important documents in archives, museums, libraries, and private collections. Parchment, prised for its durability and versatility, and used as writing support for centuries, is a material, constituted of structured collagen fibres that is extremely hygroscopic and reacts readily to changes of humidity, resulting in cockling and curling, and is endangered by biological, thermochemical, and mechanical damage. ${ }^{18}$ We identified twenty methods of degradation that commonly affect parchment documents, changing their physical characteristics at both microscopic and macroscopic levels. ${ }^{19}$ The damage agents were selected so as to affect the properties of the parchment, but also the legibility of text in various ways, for example, shrinking or otherwise deforming the parchment, and obscuring or effacing the writing via physical, chemical, or biological reactions. ${ }^{20}$ These degradation methods fall within the main categories of (a) mechanical, (b) thermochemical and humidity, and (c) physical and extraneous substances, all of which act directly upon the writing support, changing its physical characteristics at both microscopic and macroscopic levels. Table 1 summarises the effects of a selection of the damage treatments, ${ }^{21}$ and Table 2 puts the treatments into context with the possible causes of damage that can occur to parchment documents during their lives.

In Table 2, the damage categories-mechanical, thermochemical and humidity, physical and extraneous substances - highlight what was mainly and primarily affected during the deterioration inflicted on the samples. In conservation, causes of damage are conventionally categorised in discrete groups, even if these are necessarily interrelated, focusing on the main source of damage. For instance, biological damage is caused by mould growing on the material, or insects eating through the material, but for mould to grow, or insects to be lively, the environmental conditions need to be within certain parameters - i.e. high relative humidity and relatively high temperature; at the same environmental conditions the material could already be suffering at the microscopic

\begin{tabular}{|l|l|}
\hline \multicolumn{1}{|c|}{ Treatment } & \multicolumn{1}{c|}{ Description } \\
\hline Mould & $\begin{array}{l}\text { In high relative humidity and temperature - micro-organisms and } \\
\text { moulds feed on the organic material causing microscopic changes. }\end{array}$ \\
\hline Heat & $\begin{array}{l}\text { Dry heat above } 200^{\circ} \mathrm{C} \text { removes most of the water from the collagen } \\
\text { structure. The proteins in the parchment then denature, shrinking } \\
\text { and changing the macroscopic shape of the parchment. }\end{array}$ \\
\hline Smoking & $\begin{array}{l}\text { Smoke alters the colour of the medium, while soot further obscures } \\
\text { the writing. }\end{array}$ \\
\hline
\end{tabular}

Table 1: A selection of methods used to degrade the parchment. 


\begin{tabular}{|c|c|c|c|c|c|c|c|c|c|c|c|c|}
\hline 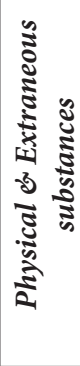 & 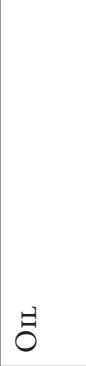 & & & & & & & & & 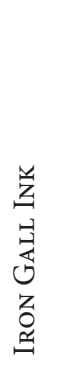 & & 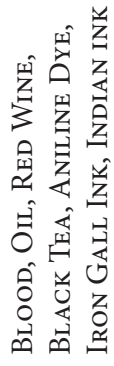 \\
\hline 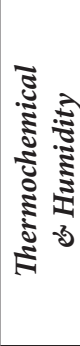 & 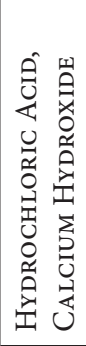 & 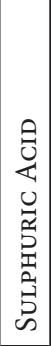 & & 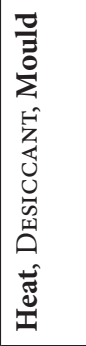 & 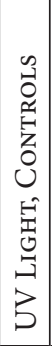 & 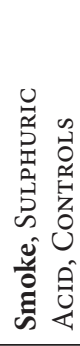 & 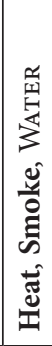 & $\begin{array}{l}\frac{\pi}{\vec{z}} \\
\frac{0}{\Sigma}\end{array}$ & & & & 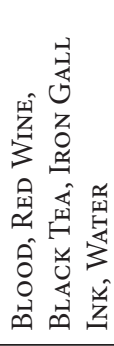 \\
\hline 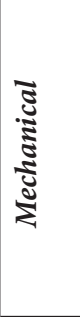 & 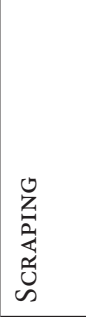 & & 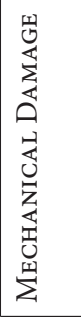 & & & & & & 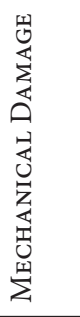 & 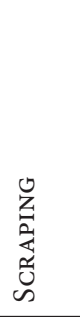 & 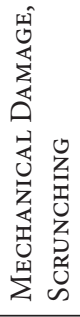 & \\
\hline 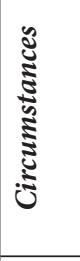 & 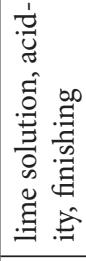 & 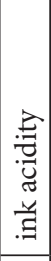 & 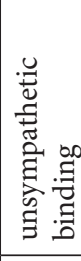 & 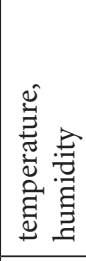 & 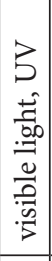 & 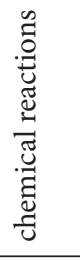 & 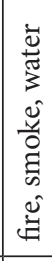 & 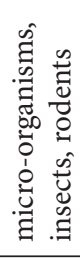 & 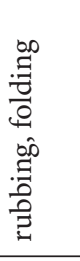 & 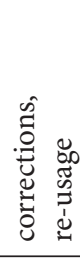 & & 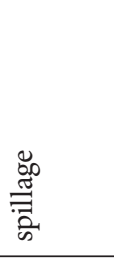 \\
\hline \multirow{2}{*}{ 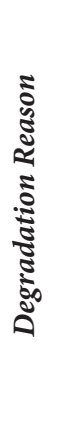 } & 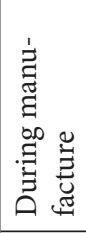 & 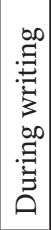 & 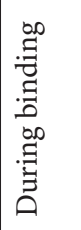 & 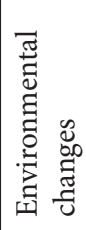 & 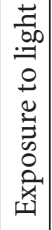 & 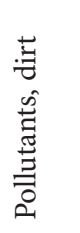 & 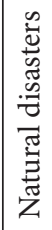 & 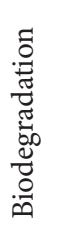 & 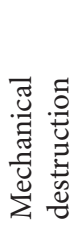 & 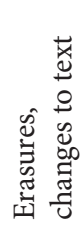 & 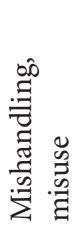 & 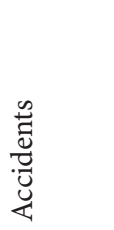 \\
\hline & \multicolumn{3}{|l|}{ 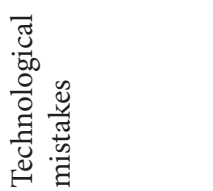 } & \multicolumn{5}{|l|}{ 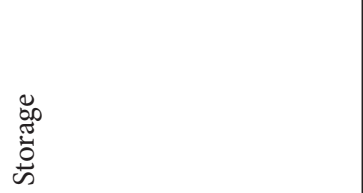 } & & $\ddot{\infty}$ & & \\
\hline
\end{tabular}




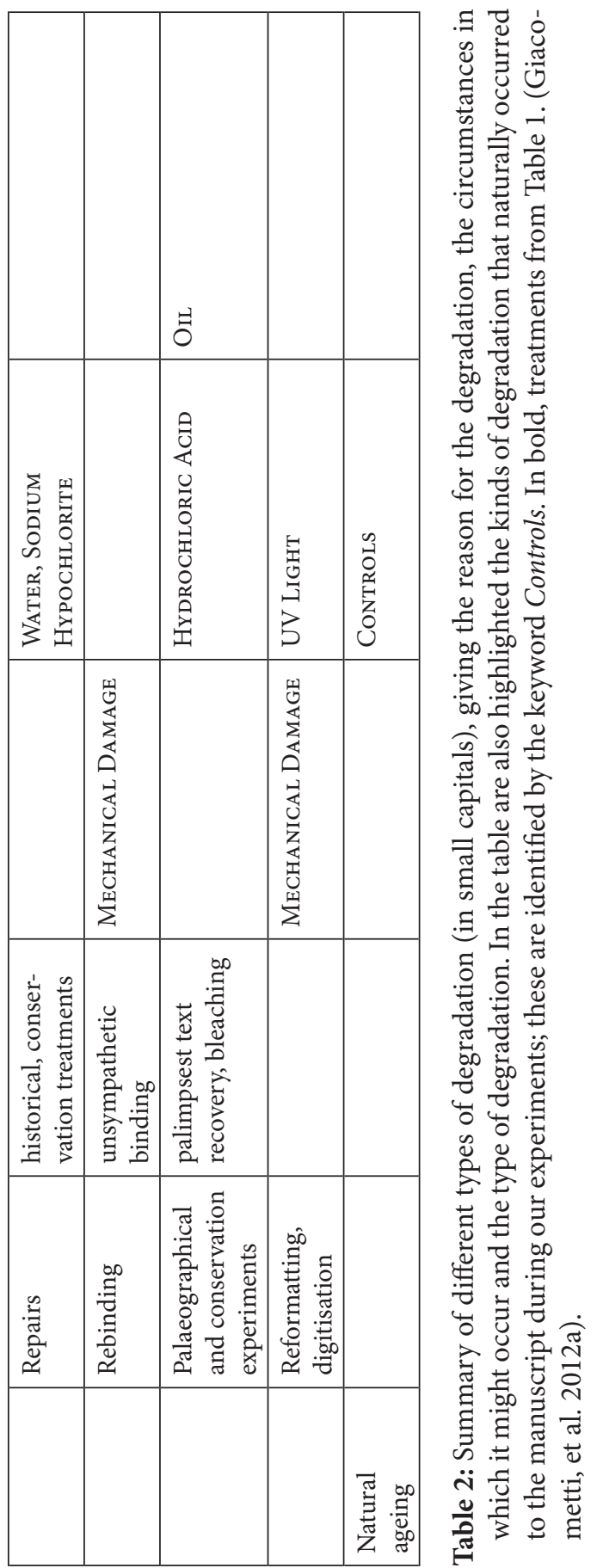


level, but these factors are shadowed by the impact of external living organisms on it. Also, when mould grows on paper and parchment, the deterioration process is certainly caused by the chemical reactions following digestion, but deterioration by mould is still usually classified as biological and not chemical damage. In the literature, however, damage classification systems vary from publication to publication: there is no universal standard on damage categorisation and its terminology. ${ }^{22}$

Additionally, we group damage agents that would have similar macroscopic effects on the parchment samples, and that would thus have similar spectral characteristics. ${ }^{23}$ In some cases, at the macroscopic level, in our experiments, we have damages that have to be signalled as belonging to more than one category-e.g. any liquid would have similar impact on parchment, but with different overall final result depending on the liquid: all liquids, from neutral water to ink, would have resulted in cockling of the sample and similar physical effects, but inks would have also obscured the writing on the sample, whilst other fluids would have also affected the parchment chemically. The categories help creating subgroups when damaging agents belong to the same group of damage category. We thus group together damages that are usually considered separately in conservation studies, as our groupings highlight similar spectral responses, which is not usually a grouping criterion for conservators. For our purposes, the damage categories can be defined as follows:

Mechanical damage: a physical deterioration originating from a physical force applied to an object, e.g. rubbing, folding, tearing - mostly affecting the legibility of the object but without compromising the chemical structure. This can sometimes provoke changes in the object's structure.

Damage by chemical, biological, or environmental factors: damage caused by substances that react with the original material resulting in a chemical change. Environmental factors such as light, humidity, and temperature can also provoke changes on an atomic or molecular level. The damage is caused by hydrolysis, oxidation or photochemical processes. Biological damage concerns damage to objects caused by living organisms such as moulds, insects, rodents and other living creatures.

Damage by extraneous substances: foreign substances introduced to an object disturbing its legibility.

Once we identified the types of damage that we were going to apply to our document, we cut twenty-three $8 \times 8 \mathrm{~cm}$ flat square sections from the two pages of the document, each containing written text and avoiding folds (see Figure 2).

The samples were imaged before and after being damaged, thus making it possible to evaluate the efficacy of imaging processing algorithms in recovering the writing from parchment documents suffering from various forms of damage. 


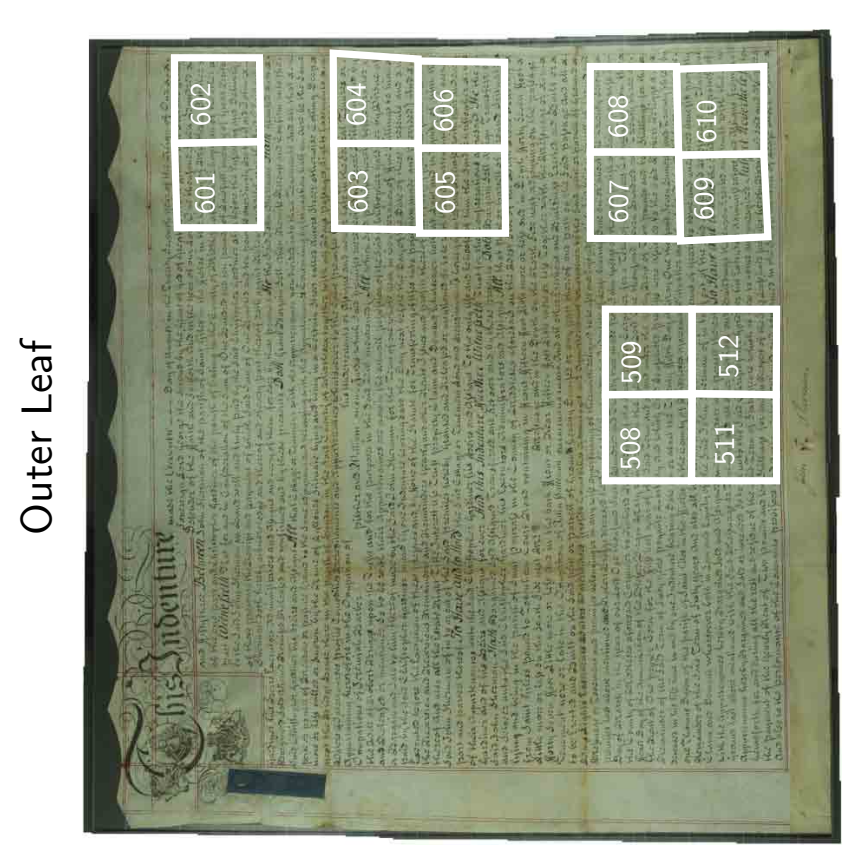

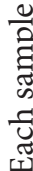

:

:

घ

范

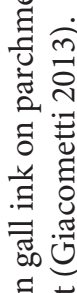

올

छ

廿ّ

\& $\frac{2}{3}$

䒕

풍

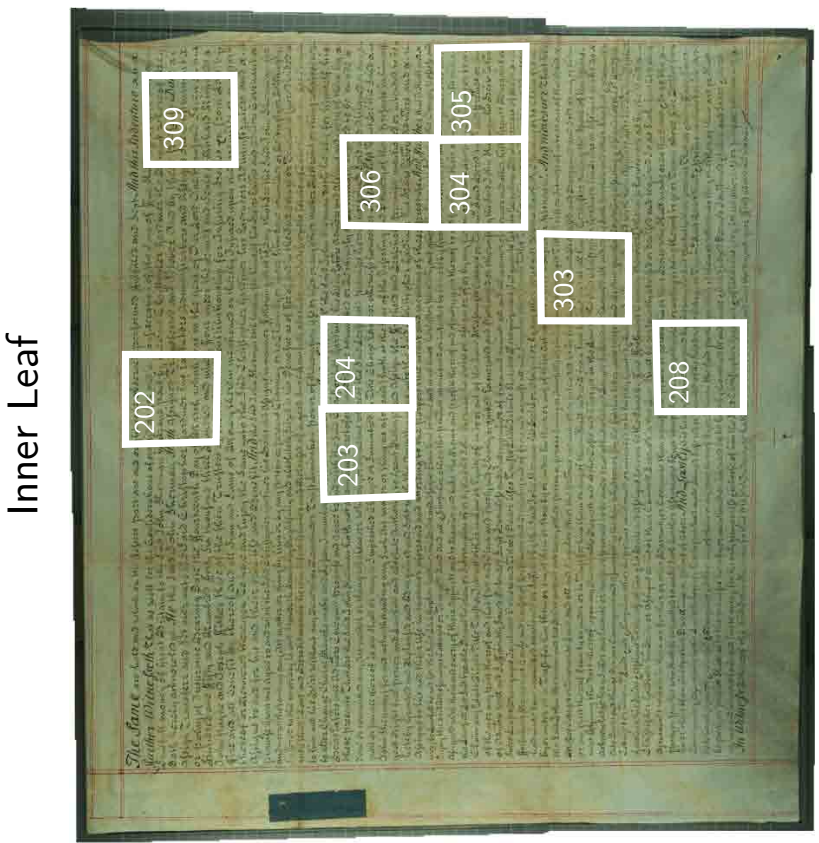

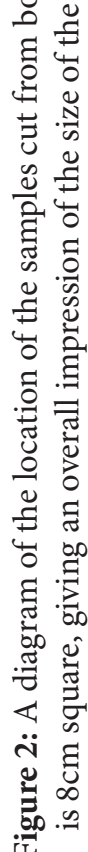


This experiment was approached from a highly multidisciplinary perspective, applying a methodology taken from medical imaging to a problem in conservation. Expertise in medical imaging and conservation was combined with insights from colour science, chemistry, and image processing in order to develop standardised tests to inform the development of multispectral imaging.

\section{Case Study 3: The do-it-yourself spirit of the materials, equipment, and procedures}

As the project developed, it became clear that the multispectral images had to be acquired within the project's limited budget. Expertise means having the know how on a subject, and being able to simplify problems and foresee experimental results. ${ }^{24}$ In other words, this required an active collaboration with experts from all the domains involved in order to obtain the necessary materials and equipment. As a consequence, this entailed a do-it-yourself approach to the production and the acquisition of the experimental data.

\subsection{Data production}

We were fortunate to be based in a medical physics laboratory, which offered access to basic laboratory equipment and materials, such as a fume cupboard, computer-controlled oven, laboratory glassware, scalpels, nitrile gloves, pipettes, $\mathrm{pH}$ indicators, as well as chemicals, human blood, and so on.

As mentioned above, our connections with the conservation world allowed us access to an original, 18th-century parchment document on which to experiment. We cut it into square samples and proceeded to inflict on these the series of damaging procedures illustrated above.

The experience accrued during conservation training and over years of bench work in conservation studios allowed us to optimise the damaging procedures so as to ensure that we limited the effects of each treatment to a single agent or procedure, e.g. we wanted to see the effect of the heat suffered in fire from the smoke. This was an important factor to take into consideration for the production of the physical samples to image: the difference between the images acquired before and after damage had to be well understood for the data analysis to be meaningful, reproducible, and comparable to other exemplars and samples. This required a number of creative solutions that were devised in an ad-hoc manner. Carefully considering the requirements for each one of the procedures, we fashioned simple devices or procedures that allowed us to perform the treatment within our budgetary constraints.

For instance, when parchment is exposed to high temperatures, its collagen structure goes through drastic changes with significant impact on the overall 
appearance and topography of the sample's surface: heat above $200^{\circ} \mathrm{C}$ removes most of the water from the collagen structure, it denatures and turns it into a random structure, shrinking and coiling the parchment, which solidifies into a new three-dimensional structure, and becomes extremely brittle, making it impossible to flatten it again. ${ }^{25}$ Such a drastic series of changes would have made it extremely difficult to register images taken before and after heating, meaning that we could not be sure that a pixel in one image corresponded unambiguously with the same pixel in another. We therefore had to devise a method to expose the parchment sample to heat, causing its collagen structure to change, without radical changes in the three-dimensional structure of the sample. With this in mind, we placed the parchment sample between two Pyrex Petri dishes, one inside the other; inside the top dish we placed a series of metal weights (up to about $1 \mathrm{~kg}$ ), whose purpose was to weigh down the parchment, thus impeding its warping in the third dimension. As a result, as the parchment shrivelled and shrunk in the computer-controlled oven at $225^{\circ} \mathrm{C}$, but the trays kept it flat and ready to be imaged (see Figure 3).

Fires in archives and libraries have devastating effects on parchment documents not only for the intense heat to which they are subjected, but also because of smoke stains and soot: particles and dust affect the document's legibility by obscuring text and reducing contrast. ${ }^{26}$ Following the principle of isolating different causes of deterioration, we prepared another sample for cold smoking, thus delivering smoke without the effects of heat on parchment. A smoking environment was devised - inspired by instructions from an amateur smoking online community ${ }^{27}$-using a soldering iron, an empty tin, smoking wood chips, aluminium containers, linen thread, and a large plastic box with lid (Figure 4). A hole was drilled on the side of the base of the tin, in order to insert the tip of the soldering iron. The tin was filled with wet wood chips. A linen thread mesh was hand sewn through the aluminium container to create a suspended base for the sample to rest on while being smoked. The components were then placed inside the plastic box to contain the smoke, creating the smoking environment. The soldering iron creates constant heat and slowly burns the wood chips. The sample was left inside the smoking environment for a total of nine hours. The smoke drastically discoloured the parchment, more intensively on the recto, which was facing up, than the verso (see Figure 5). The discolouration pattern on the verso suggested that the smoke penetrated from the recto more prominently through the weaker parts of the parchment (pores, old folds, blemishes).

Documents stored in a damp environment are quickly affected by mould growth. As moulds grow, they feed on dirt particles, and the organic compounds of parchment and inks, leaving coloured stains due to the chemical byproducts of the digestion process. Consequently, parchment documents affected by mould are fragile, porous, and often left with permanent discolourationswhich can be extremely intrusive-and, in the worst cases, holes. In order to 

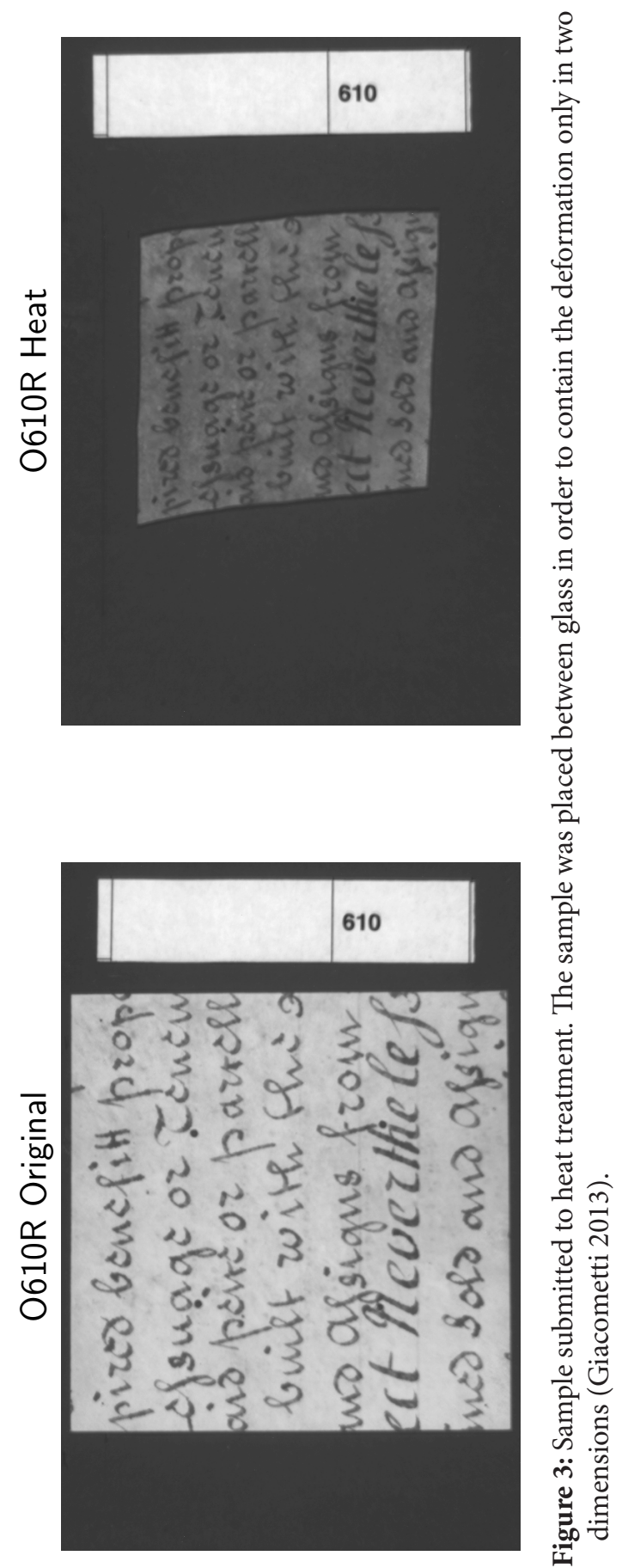


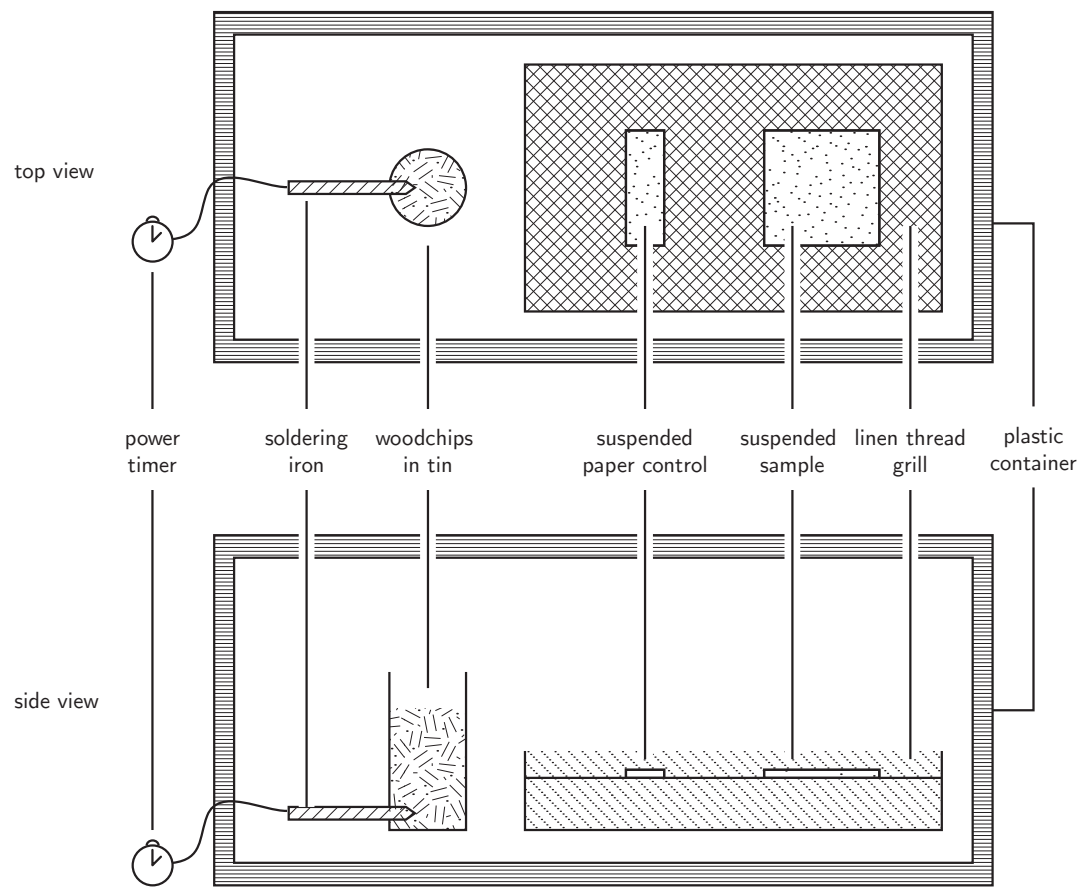

Figure 4: Smoking device constructed in order to treat the selected sample. Its construction was inspired by devices created by amateur smoking enthusiasts sharing their expertise online (see note 27; Giacometti 2013).

accelerate mould growth, a parchment sample was placed inside an airtight plastic container on top of a stack of damp blotters along with a slice of mouldy bread. Moulds that typically grow on bread, such as those of the genera Aspergillus and Penicillium, as proteolytic fungi, also affect parchment documents. ${ }^{28}$ The sample was left inside the container for approximately five weeks in a dark environment at stable room temperature. At the end of the incubation period, the sample presented the characteristic coloured stains, it was rather fragile and porous, and in places it had been completely destroyed (Figure 6).

Limiting the degradation effects by isolating them, whenever possible, allowed for more useful samples for the subsequent imaging process. In a similar way, we had to devise a way to allow successful alignment of the images before and after degradation. In order to create stable reference points for such a registration process, we decided to punch four $1 \mathrm{~mm}$ holes using a Japanese screw punch into each sample at about a third of the distance from the borders, thus forming a square of holes in the centre of each sample (Figure 7). ${ }^{29}$ These holes were later used to visually compare the images of the samples. 


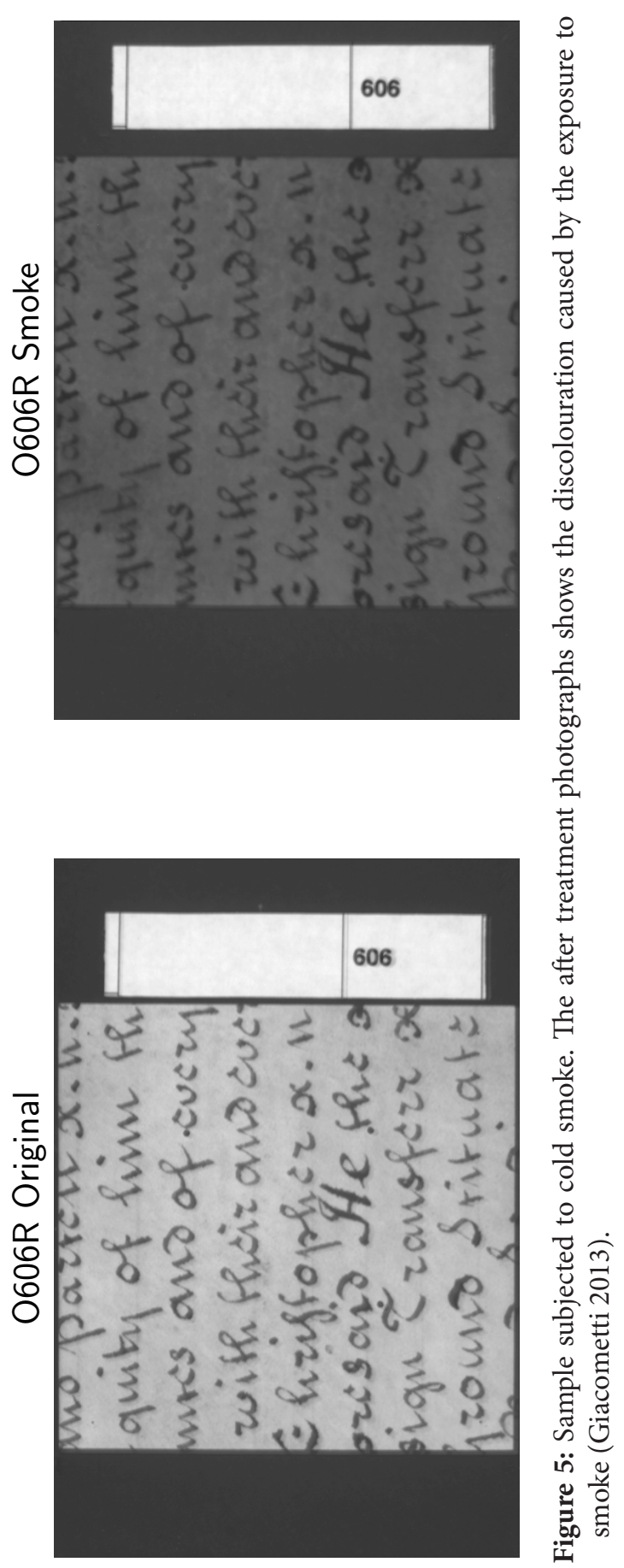




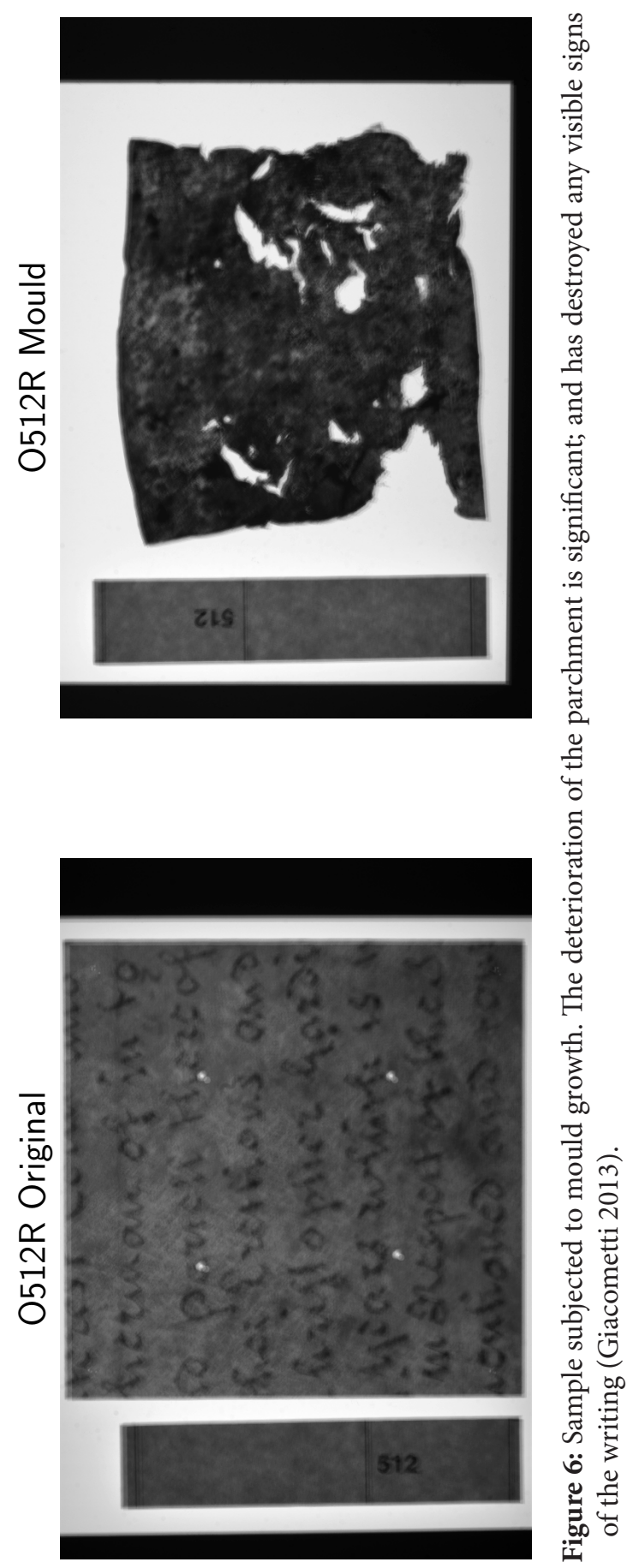



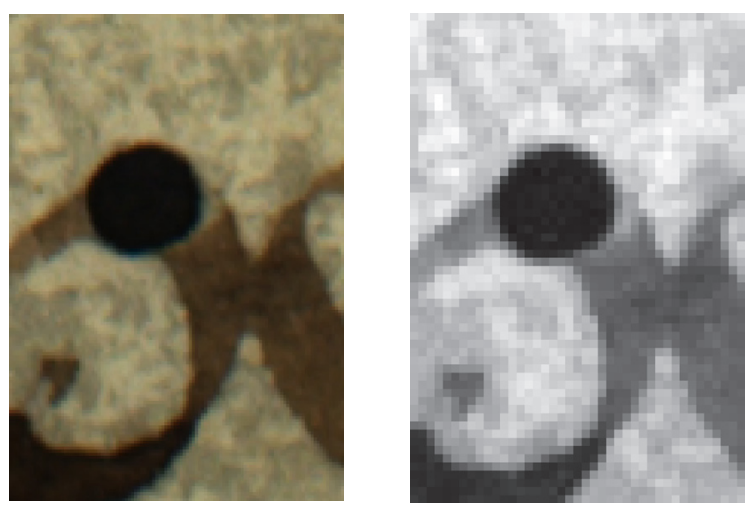

Figure 7: One mm holes were punched into each sample, used as a calibration mark that would survive the conditions that every sample was being subjected to. These images show the difference in resolution of the two cameras used by displaying the punched holes at a similar scale (Giacometti 2013).

A card stencil, the same size of the samples, was used to keep the shape of the square consistent across the samples. These holes were chosen as an effective registration method as they did not affect the integrity of the samples, did not introduce new materials, and they reacted concurrently with the sample when this suffered any changes. This provided a valuable guide when attempting to digitally register the image sets, the holes functioning as detectable features found in both the source and the target image.

These examples show how simple, creative solutions and experimentation aided the development of our approach by borrowing from conservation bench-work experience, simple devices, and advice from an online enthusiast community.

\subsection{Data acquisition}

This project acted as a pilot which led subsequently to the development of the Multispectral facilities in the UCL Centre for Digital Humanities Multimodal Imaging Suite. ${ }^{30}$ However, even this pilot study required access to specialist multispectral imaging hardware. ${ }^{31}$ Due to budgetary constraints, we had to assemble a working multispectral imaging suite with minimum expenditure. ${ }^{32}$ Having the right set of skills and expertise in the team-between colour science, and data processing and manipulation- made it possible to devise a low-cost, working multispectral imaging system.

The imaging setup was composed of two cameras: a Nikon D200 digital SLR camera with Nikon $105 \mathrm{~mm} \mathrm{f} / 2.8$ lens in combination with 16 Unaxis Optics bandpass filters; and a Kodak Megaplus 1.6i scientific monochrome camera with Nikon $50 \mathrm{~mm} \mathrm{f} / 2$ lens, using 5 Andover Corporation infrared bandpass filters in addition to the previous 16 (Figure 8). 


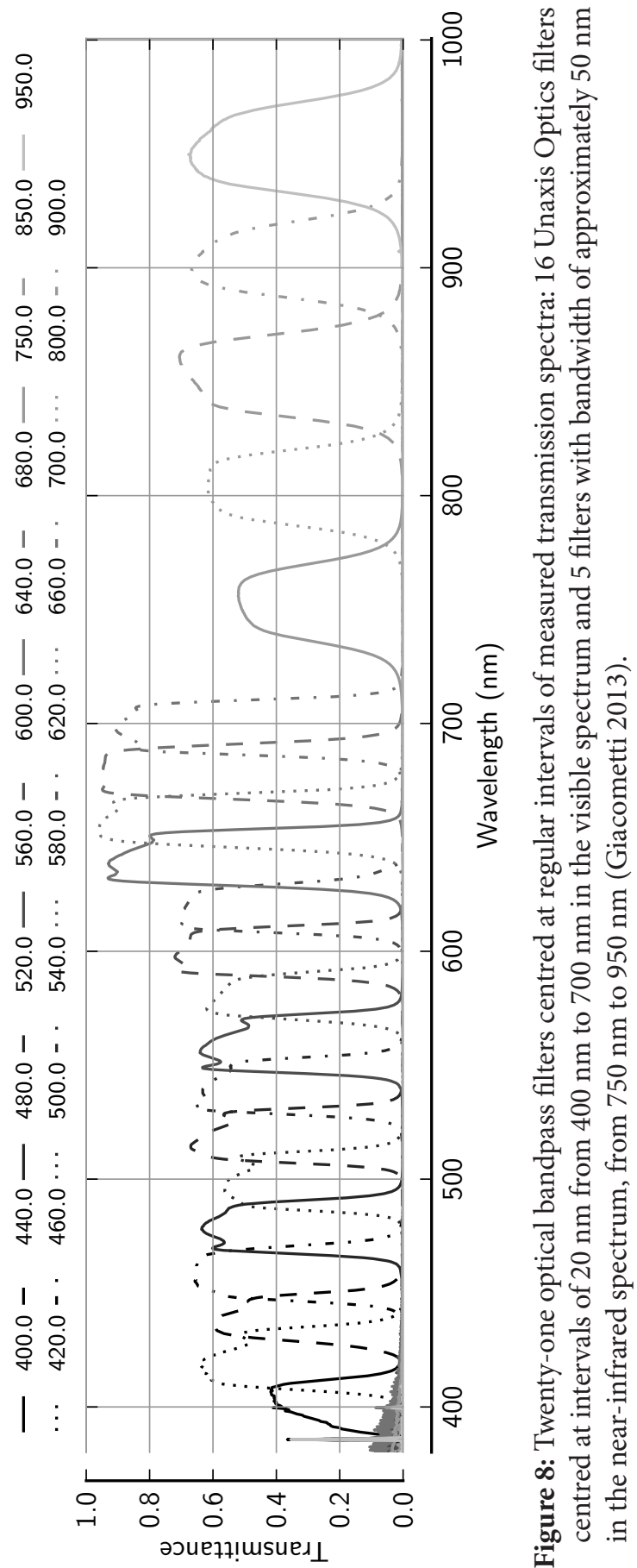


The 16 Unaxis Optics filters each had a bandwidth of about $20 \mathrm{~nm}$, and were centred at regular intervals of $20 \mathrm{~nm}$ from $400 \mathrm{~nm}$ to $700 \mathrm{~nm}$. The five infrared filters had a bandwidth of approximately $50 \mathrm{~nm}$, centred at intervals of $50 \mathrm{~nm}$ in the near-infrared spectrum, from $750 \mathrm{~nm}$ to $950 \mathrm{~nm}$. During initial testing, it was discovered that the four filters above $640 \mathrm{~nm}$ in the visible spectrum also transmitted near-infrared light; with these filters, a second infrared blocking filter was used in combination. The five infrared filters were used only with the monochrome camera, as its sensor was sensitive to ranges from approximately $400 \mathrm{~nm}$ to $1,000 \mathrm{~nm}$; the Nikon D200 had a built-in infrared blocking filter, and it was thus not capable of capturing images above $700 \mathrm{~nm}$.

The system used two illumination techniques: standard document copystand lighting, and a lightbox backlight. The copystand illuminated the document using four tungsten-halogen lamps set at $45^{\circ}$ angles (Figure 9); these lamps provided broadband emission from the ultraviolet into the near infrared. The lightbox backlight was made of two fluorescent lamps behind a flat diffuser, creating a uniform flat source of white light; these lamps illuminated mainly in the visible spectrum, and, for this reason, backlighting was only used with the colour camera. Transmissive lighting allowed illuminating the parchment samples from behind, thus interacting with both the surface, and the structure of the parchment.

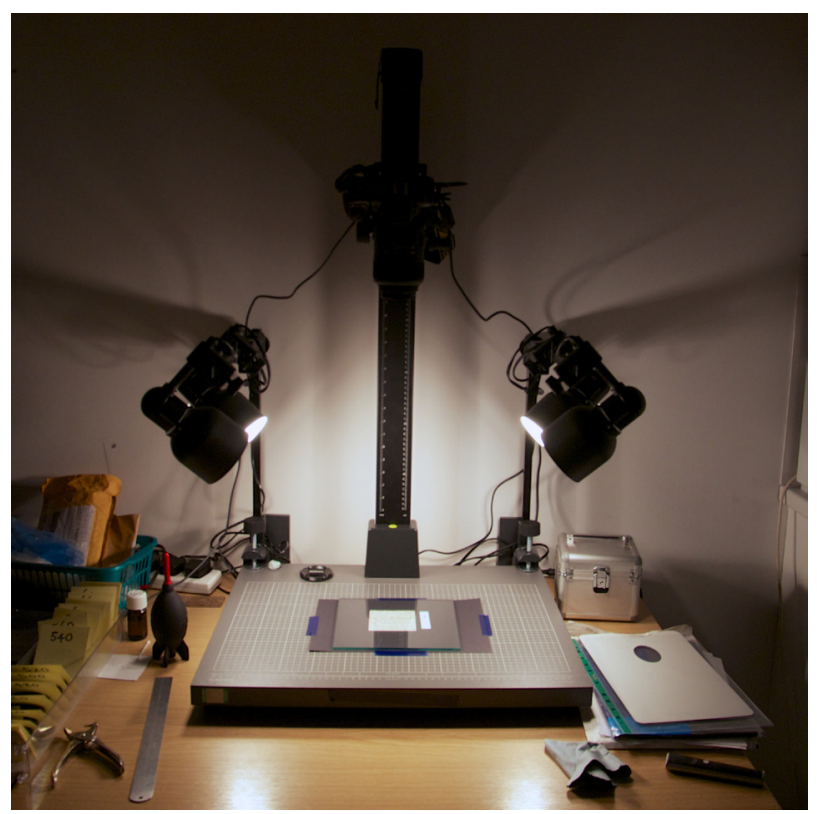

Figure 9: Imaging setup. The camera is locked facing vertically downwards. Four tungsten-halogen lamps illuminate the sample at an angle of $45^{\circ}$. The sample is placed on the copystand over a piece of black card under a sheet of anti-reflective glass (Giacometti 2013). 
In total, approximately 3,000 images of samples were acquired during the project in two imaging sessions: before, and after parchment degradation. The data from our experiments forms a set of multispectral images showing both the initial and degraded state of a manuscript. With a do-it-yourself attitude towards the equipment, creativity when dealing with problems, and high collaboration with experts in various fields, this project managed to create a large dataset of reference multispectral images of parchment damage within a relatively limited budget. We believe that these can become a valuable resource for both conservation research and libraries and archives undergoing digitisation efforts. ${ }^{33}$

\section{Conclusions}

Multispectral imaging is increasingly becoming a common tool in cultural heritage, and it is therefore important to understand its applicability to the capture and analysis of our varied written heritage. Our research provides a systematic methodology to evaluate and review the techniques and processing of multispectral images of historical documents, thus allowing a most efficient use of resources.

In our research, we purposefully degraded a real historical manuscript on parchment, which was a necessary step to model successfully the type of damage commonly seen in historical documents. This helped us to understand how different types of damage affect historical documents and their text, both before and after multispectral imaging of the samples. The critical destruction was a fundamental part of the project, since it was essential to the understanding of the effectiveness of multispectral imaging on historical documents. ${ }^{34}$

Often, academic groups experience echo chambers, since their members tend to share information, modi operandi, and opinions. This situation is to some extent less critical within the digital humanities - an interdisciplinary field by definition-but looking outside the natural echo chamber for collaborations and knowledge exchanges can prove fruitful and leads to successful projects, ${ }^{35}$ as it was the case for the examples outlined in this chapter.

The knowledge exchange for this project was not unidirectional. Gathering information from adjoining fields certainly allowed us to design the phases and components of the project efficiently, however, the results and the analysis are beneficial to fields other than multispectral imaging of deteriorated parchment documents. To conservators and other professionals involved in the preservation of documents, for example, it is helpful to think about how to categorise damage according to what kind of analysis can or needs to be performed on a document to retrieve information (both written information and relative to its state of conservation) as, considering the usually limited resources of these groups of professionals, this would save time and costs.

De facto, by being open about the limited resources we had at our disposal, and the do-it-yourself spirit of our materials, equipment, and procedures, we want to highlight how interdisciplinarity and collaboration played a key and fundamental role for the success of our project. We also want to allow replication of 
our experiments and foster subsequent research and scholarship in the field. We envisage, in fact, that the dataset generated during the project has the potential to become an invaluable asset for libraries and archives, research in conservation, and various image and signal processing sets of problems, and have made all of the data generated from this project freely available online. Our dataset ${ }^{36}$ provides physical information of how parchment reacts to various forms of degradation, but also provides consistent process and documentation on acquisition, and will provide a test environment for any future research whilst reducing the need for experimentation on valuable primary historical texts.

\section{Notes}

${ }^{1}$ See: Giacometti et al. 2011; Giacometti et al. 2012a; Giacometti et al. 2012b; Campagnolo et al. 2013a; Campagnolo et al. 2013b; MacDonald et al. 2013; Giacometti et al. 2014; with an overview of the whole project available in open access in Giacometti et al. 2015.

2 The DOI for this dataset is http://dx.doi.org/10.14324/000.ds.1469099.

3 Terras 2012.

${ }^{4}$ Firbank \& Delpy 1993; Krackow, Duncan \& Gorten 1973; Levesque, Sled \& Pike 2011; Pogue \& Patterson 2006; Richard \& Webber 1963.

${ }^{5}$ Krackow, Duncan \& Gorten 1973; Pekar \& Patterson 2010; Richards \& Webber 1963.

${ }^{6}$ Price et al. 2010.

${ }^{7}$ Levesque, Sled \& Pike 2011.

${ }^{8}$ Fessas, Signorelli, et al. 2006; Dolgin, Bulatov \& Schechter 2007; Schellmann 2007; Marengo et al. 2011.

${ }_{9}$ Fessas, Signorelli, et al. 2006.

${ }^{10}$ Dolgin, Bulatov \& Schechter 2007.

11 Schellmann 2007.

${ }^{12}$ Marengo et al. 2011.

13 Baumann, Porter \& Seales 2008; Cao, Ding \& Liu 2003; Samko et al. 2014.

${ }^{14}$ Giacometti, et al. in press.

15 Giacometti, et al. 2015.

16 The National Archives 2015.

17 The National Archives 2015.

18 Reed 1972; Clarkson 1992; Larsen 2007; Giacometti, et al. 2012

19 Vnouček 2007.

${ }^{20}$ Giacometti, et al. 2015.

${ }^{21}$ A full list of deterioration methods and their explanation can be found in Giacometti et al. 2012, Table 1, pp. 303-304.

22 Van Camp 2010.

${ }^{23}$ See the Data acquisition section below, for a description of the imaging system used for the project. 
${ }^{24}$ Ericsson 2006.

${ }^{25}$ Avery et al. 2013; Pal et al. 2013a; Pal et al. 2013b.

${ }^{26}$ Kautek et al.1998.

${ }^{27}$ Fun with Cold Smoking: <http://www.nibblemethis.com/2009/11/funwith-cold-smoking-macgyver-style.html> (last accessed October 2015).

${ }^{28}$ Berger et al. 1937; Rogerio-Candelera 2014.

${ }^{29}$ Japanese Screw Punch: <http://www.conservation-by-design.com/category. aspx?id=446> (last accessed July 2015).

${ }^{30}$ UCL Centre for Digital Humanities Multimodal Imaging Suite: <https:// www.ucl.ac.uk/dh/facilities/digitisation-suite> (last accessed July 2015).

31 Terras 2012.

32 Existing equipment was used throughout the project in order to maintain costs down. The cameras, the copystand, some of the filters and some of the lighting were available. In order to reproduce this setup, the bandpass filters would represent the highest cost—around $£ 10,000$. A similar Nikon camera and lens combination to the one used could be acquired for approximately $£ 2,000$.

33 The DOI for this dataset is http://dx.doi.org/10.14324/000.ds.1469099.

${ }^{34}$ Giacometti et al. 2015.

35 Terras 2012; Terras 2010.

${ }^{36}$ DOI: http://dx.doi.org/10.14324/000.ds.1469099.

\section{References}

Avery, N., Campagnolo, A., De Stefani, C., Pal, K., Payne, M., Smith, P., Smither, R., Stewart, A.M., Stewart, E., Stewart, P., Terras M., Ward L., Weyrich, T. \& Yamada E., 2013. The Great Parchment Book. Poster presented at Digital Humanities 2013, University of Nebraska, Lincoln, July 2013, Lincoln.

Baumann, R., Porter, D.C. \& Seales, W.B. (2008). The Use of Micro-CT in the Study of Archaeological Artifacts. In: 9th International Conference on NDT of Art. Presented at the 9th International Conference on NDT of Art, Jerusalem, Israel, pp. 1-9.

Berger, J., Johnson, M.J. \& Peterson, W.H. (1937). The proteolytic enzymes of some common molds. The Journal of Biological Chemistry 117: 429-438.

Campagnolo, A., Giacometti, A., MacDonald, L., Mahony, S., Terras, M., Robson, S., Weyrich, T. \& Gibson, A. (2013a). Cultural Heritage Destruction: Measuring Information Recovery from Multispectral Images of Deteriorated parchment. In: British Library, Topic Talk, Collections Care, 11th September 2013. Presented at the British Library, Topic Talk, Collections Care.

Campagnolo, A., Giacometti, A., MacDonald, L., Mahony, S., Terras, M., Robson, S., Weyrich, T. \& Gibson, A. (2013b). Documenting and Interpreting Parchment Deterioration by Visual Analysis and Multispectral Imaging, in: Icon PF13, Positive Futures in an Uncertain World, Glasgow, 10-12 
April 2013. Presented at the Icon PF13, Positive Futures in an Uncertain World, Glasgow, 10-12 April 2013, Glasgow.

Cao, H., Ding, X. \& Liu, C. (2003). A cylindrical surface model to rectify the bound document image. In: Ninth IEEE International Conference on Computer Vision, 2003. Proceedings. Presented at the Ninth IEEE International Conference on Computer Vision, 2003. Proceedings, pp. 228-233. DOI: http://dx.doi.org/10.1109/ICCV.2003.1238346

Clarkson, C. (1992). Rediscovering Parchment: The Nature of the Beast. The Paper Conservator 16: 5-26. DOI: http://dx.doi.org/10.1080/03094227.1992.9638571

Conservation By Design Ltd. (2015). Japanese Screw Punch. Retrieved from http://www.conservation-by-design.com/category.aspx?id=446

Dolgin, B., Bulatov, V. \& Schechter, I. (2007). Non-destructive assessment of parchment deterioration by optical methods. Anal. Bioanal. Chem. 388: 1885-1896. DOI: http://dx.doi.org/10.1007/s00216-007-1410-0

Ericsson, K.A. (2006). An introduction to The Cambridge Handbook of Expertise and Expert Performance. In: K. A. Ericsson, N. Charness, P. J. Feltovich, R. R. Hoffman (Eds.), The Cambridge Handbook of Expertise and Expert Performance (pp. 3-20). New York: Cambridge University Press.

Fessas, D., Signorelli, M., Schiraldi, A., Kennedy, C.J., Wess, T.J., Hassel, B. \& Nielsen, K. (2006). Thermal analysis on parchments I: DSC and TGA combined approach for heat damage assessment. Thermochimica Acta 447: 30-35. DOI: http://dx.doi.org/10.1016/j.tca.2006.04.007

Firbank, M. \& Delpy, D.T. (1993). A design for a stable and reproducible phantom for use in near infra-red imaging and spectroscopy. Phys. Med. Biol. 38: 847. DOI: http://dx.doi.org/10.1088/0031-9155/38/6/015

Giacometti, A. (2013). Evaluating Multispectral Imaging Processing Methodologies for Analysing Cultural Heritage Documents. (Doctoral dissertation, University College London, London).

Giacometti, A., Campagnolo, A., MacDonald, L., Mahony, S., Robson, S., Weyrich, T., Terras, M. \& Gibson, A. (2015). The value of critical destruction: evaluating multispectral image processing methods for the analysis of primary historical texts. Digital Scholarship in the Humanities. DOI: http:// dx.doi.org/10.1093/llc/fqv036

Giacometti, A., Campagnolo, A., MacDonald, L., Mahony, S., Robson, S., Weyrich, T., Terras, M. \& Gibson, A. (in press). Visualising macroscopic deterioration of parchment and writing via multispectral images, in: Care and Conservation of Manuscripts 15, University of Copenhagen 2nd-4th April 2014. Presented at the Care and Conservation of Manuscripts 15, University of Copenhagen 2nd-4th April 2014. University of Copenhagen, Copenhagen, Denmark: Museum Tusculanum Press.

Giacometti, A., Campagnolo, A., MacDonald, L., Mahony, S., Terras, M., Robson, S., Weyrich, T. \& Gibson, A. (2012a). Cultural Heritage Destruction: Documenting Parchment Degradation via Multispectral Imaging, in: Electronic Visualisation and the Arts (EVA 2012). Presented at the Electronic 
Visualisation and the Arts (EVA 2012), British Computing Society, London, UK, pp. 301-308.

Giacometti, A., Campagnolo, A., MacDonald, L., Terras, M., Mahony, S., Weyrich, T., Robson, S. \& Gibson, A. (2012b). Cultural Heritage Destruction: Documenting Parchment Degradation via Multispectral Imaging, in: Digital Classicist \& Institute of Classical Studies Seminar. Presented at the Digital Classicist \& Institute of Classical Studies Seminar, London, UK.

Giacometti, A., Gibson, A., Hess, M., Hindmarch, J., MacDonald, L., Pal, K., Robson, S., Terras, M. \& Weyrich, T. (2014). Heritage Imaging at UCL, in: Annual Conference of Association for Historical and Fine Art Photography (AHFAP). Presented at the Annual Conference of Association for Historical and Fine Art Photography (AHFAP).

Giacometti, A., Terras, M., Gibson, A. \& Mahony, S. (2011). Multi-Spectral Image Processing Methods For Analysing Ancient Documents, in: Society for Digital Humanities/Société Pour Létude Des Médias Interactifs (SDH/ SEMI) Annual Conference at the 2011 Congress of the Social Sciences and Humanities. Presented at the Society for Digital Humanities / Société pour l'étude des médias interactifs (SDH/SEMI) annual conference at the 2011 Congress of the Social Sciences and Humanities.

Kautek, W., Pentzien, S., Rudolph, P., Krüger, J. \& König, E. (1998). Laser interaction with coated collagen and cellulose fibre composites: fundamentals of laser cleaning of ancient parchment manuscripts and paper. Applied Surface Science 127-129, 746-754. DOI: http://dx.doi.org/10.1016/S0169-4332(97)00735-6

Krackow, K.A., Duncan, M.L. \& Gorten, R.J. (1973). Use of digital phantoms and a simulation of the scanning process to evaluate techniques of computer focusing of area scans. International Journal of Nuclear Medicine and Biology 1: 29-35. DOI: http://dx.doi.org/10.1016/0047-0740(73)90040-5

Larsen, R. (2007). Introduction to damage and damage assessment. In: Larsen, R. (Ed.), Improved Damage Assessment of Parchment (IDAP): Assessment, Data Collection and Sharing of Knowledge. European Commission, Directorate-General for Environment, pp. 17-21.

Levesque, I.R., Sled, J.G. \& Pike, G.B. (2011). Iterative optimization method for design of quantitative magnetization transfer imaging experiments. Magnetic Resonance in Medicine 66: 635-643. DOI: http://dx.doi.org/10.1002/mrm.23071 MacDonald, L.W., Giacometti, A., Campagnolo, A., Robson, S., Weyrich, T., Terras, M. \& Gibson, A. (2013). Multispectral Imaging of Degraded Parchment In: S. Tominaga, R. Schettini, A. Trémeau, (Eds.), Computational Color Imaging, 4th International Workshop, CCIW 2013, Chiba, Japan, March 3-5, 2013. Proceedings, Lecture Notes in Computer Science. Springer Berlin Heidelberg, Chiba, Japan, pp. 143-157.

Pal, K., Terras, M. \& Weyrich, T. (2013a). 3D Reconstruction For Damaged Documents: Imaging of The Great Parchment Book. In: Proceedings of 2nd International Workshop on Historical Document Imaging and Processing. Washington DC, 24 August, 2013, pp. 14-21. 
Pal, K., Terras, M. \& Weyrich, T. (2013b). Interactive Exploration and Flattening of Deformed Historical Documents. Computer Graphics Forum 32: 327-334. DOI: http://dx.doi.org/10.1111/cgf.12052

Pekar, J. \& Patterson, M.S. (2010). Fabrication and characterization of phantoms with tissue-like optical properties from 500 to $700 \mathrm{~nm}$. Medical Laser Application 25: 147-153. DOI: http://dx.doi.org/10.1016/j.mla.2010.04.002

Pogue, B.W. \& Patterson, M.S. (2006). Review of tissue simulating phantoms for optical spectroscopy, imaging and dosimetry. Journal of Biomedical Optics 11: 041102-041102-16. DOI: http://dx.doi.org/10.1117/1.2335429

Price, B.D., Gibson, A.P., Tan, L.T. \& Royle, G.J. (2010). An elastically compressible phantom material with mechanical and x-ray attenuation properties equivalent to breast tissue. Phys. Med. Biol. 55: 1177-1188. DOI: http:// dx.doi.org/10.1088/0031-9155/55/4/018

Reed, R. (1972). Ancient Skins, Parchments and Leathers. London: Seminar Press.

Richards, A.G. \& Webber, R.L. (1963). Constructing phantom heads for radiation research. Oral Surgery, Oral Medicine, Oral Pathology 16: 683-690. DOI: http://dx.doi.org/10.1016/0030-4220(63)90073-2

Rogerio-Candelera, M.A. (Ed.) (2014). Science, Technology and Cultural Heritage. Balkema, Leiden: CRC Press.

Samko, O., Lai, Y.-K., Marshall, D. \& Rosin, P.L. (2014). Virtual unrolling and information recovery from scanned scrolled historical documents. Pattern Recognition 47. DOI: http://dx.doi.org/10.1016/j.patcog.2013.06.015

Schellmann, N.C. (2007). Animal glues: a review of their key properties relevant to conservation. IIC Reviews in Conservation 8: 55-66.

Terras, M. (2010). The Digital Classicist: Disciplinary Focus and Interdisciplinary Vision. In: G. Bodard, S. Mahony (Eds.), Digital Research in the Study of the Classical Antiquity. Farnham: Ashgate, 171-191.

Terras, M. (2012). Being the Other: Interdisciplinary Work in Computational Science and the Humanities. In: P. W. McCarty, P. M. Deegan (Eds.), Collaborative Research in the Digital Humanities. Farnham: Ashgate, pp. 213-230.

The National Archives (2015). Deaccessioning and disposal. Guidance for archive services.

UCLDH (2015). Digitisation Suite. Retrieved from https://www.ucl.ac.uk/dh/ facilities/digitisation-suite

Van Camp, K. (2010). Damage Atlas for Photographic materials. CeROArt, Conservation, exposition et Restauration d'Objets d'Art. Retrieved from http://ceroart.revues.org/1770

Vnouček, J. (2007). Typology of the Damage of the Parchment in Manuscripts of the Codex Form. In: R. Larsen (Ed.), Improved Damage Assessment of Parchment (IDAP): Assessment, Data Collection and Sharing of Knowledge. European Commission, Directorate- General for Environment, pp. 27-30. 